\title{
ESCOLA: PERSPECTIVAS, LIMITES E TRAJETÓRIAS NO CONTEXTO DO RECENTE SÉCULO XXI
}

Caríssimos Leitores,

Iniciamos esta edição com a Seção de Artigos Encomendados sobre o tema: "ESCOLA: ocupação e resistência", assunto que avaliamos como muito relevante e pertinente, tendo em vista a crise, as mudanças e as transformações pelas quais o sistema educacional brasileiro vem sofrendo nos últimos tempos, e a postura dos estudantes e dos demais atores envolvidos diante desse quadro. Nessa primeira seção, o artigo de Rafael Bastos e Viviane Marinho aborda algumas experiências sobre as ocupações de escolas públicas estaduais, da rede básica de educação do estado do Rio de Janeiro, intitulado: "Escolas do Rio de Janeiro ocupadas: faces de uma pedagogia militante". Também nessa seção estão os artigos: "Das origens da ocupação da escola: o caso do MST", de Fernando Martins, que aborda a ocupação da escola no interior da prática do Movimento dos Trabalhadores Rurais Sem Terra - MST, e "Os desafios da escola pública na relação com as políticas sociais", de Eveline Algebaile, que analisa as relações contemporâneas da escola pública com políticas de assistência social, no Brasil, e identifica suas características, contradições e pontos de tensão. No quarto artigo encomendado, "Propostas pedagógicas comprometidas com a classe trabalhadora: Ensino Médio integrado e Complexos de Estudos", Noemi Pereira e Maristela Solda abordam duas propostas de educação pioneiras no Brasil - uma integrando o Ensino Médio e o Profissional e a outra desenvolvida em escolas do MST. Encerrando essa seção, Wallace Ferreira e Alberto Alvadia Filho analisam " $A$ serpente pedagógica: 0 projeto Escola sem Partido", considerando suas forças, movimentos conservadores, propostas de lei e possíveis impactos no ensino e no currículo do Ensino Médio brasileiro e, em particular, na Sociologia.

A Seção de Artigos se inicia com Marcelo Rocha, José Renato Pin, Yasmin Góes e Laura Rodrigues, que discutem a formação ambiental dos educandos, ao utilizar as trilhas ecológicas como espaços não formais, por meio da construção individual e coletiva de atitudes, conceitos e procedimentos. O segundo artigo da Seção, de autoria de Maria de Fátima da Silva e de Patrícia Lima, apresenta resultados de uma pesquisa voltada à elaboração de metodologias para a efetivação da Lei no 11.645/2008, reforçando a obrigatoriedade da temática das matrizes culturais africanas e indígenas, em nossos currículos. Já o terceiro artigo, de autoria de Maria Beatriz Porto e Esequiel Oliveira, relata uma experiência de ensino de Física e Robótica, desenvolvida por meio de um projeto de Iniciação Científica e Tecnológica Junior, com questões relacionadas à imagem e ao conhecimento, apontando para possibilidades no ensino e na pesquisa na Educação Básica. O quarto artigo, de Eliane Maria Morriesen, Juliane Urban, Débora Campos, Eloiza Aparecida de Matos e Antônio Carlos Frasson, aborda uma proposta de empreendedorismo nas escolas voltada para os estudantes dos quarto e quinto anos do Ensino Fundamental. O artigo de Gisele Santos é o quinto dessa seção e propõe uma abordagem de conteúdos científicos da Química utilizando recursos audiovisuais na 
temática cachaça, ressaltando o diálogo de conceitos com a história e a cultura afrobrasileira. O sexto artigo, de autoria de Gabriel Beraldi, Eduardo José Lannes, Francisco Mattos e Christine Costa encerra a seção e busca demonstrar a aplicação de um jogo digital, junto a turmas de Ensino Médio, na disciplina Desenho Geométrico. De acordo com os autores, o software utilizado na disciplina em tela e experimentado em laboratório de informática foi eficaz como ferramenta de auxílio para a compreensão do Estudo de Retas em Geometria Descritiva.

A Seção Especial da revista traz cinco artigos de autores que apresentaram seus trabalhos no "X Simpósio Educação e Sociedade Contemporânea: desafios e propostas", do CAp-UERJ. Luciana Velloso avalia as facilidades e dificuldades dos discentes para lidar com os recursos tecnológicos, as diferentes formas de comunicação entre as turmas e como tais elementos repercutem em sua socialização dentro do espaço universitário. Em seguida, está o artigo de José Antonio Vianna, Matheus da Cruz e Fernanda Nenartavis. Sua proposta é verificar a orientação espacial direita-esquerda (OE) de alunos matriculados nos anos iniciais do Ensino Fundamental. O artigo de Cláudia Cristina Andrade, Douglas Neves, Juliana Maria Prados, Patrícia Bastos e Tatiana de Freitas apresenta reflexões sobre o potencial da perspectiva discursiva, a partir da utilização da Análise do Discurso, em pesquisas que se dedicam ao campo do ensino, englobando produções de sentido, em face de elementos culturais. O quarto texto da Seção Especial, de Helena Araújo, conceitua e problematiza a memória, tomada como instrumento de empoderamento identitário, ao permear processos educativos em espaços formais, não formais ou, ainda, informais. O último artigo da seção, de autoria de Amanda Silva, objetiva analisar a valorização do magistério, conforme a Resolução no 2/2015, reconhecendo a materialidade das políticas em curso, seus impactos no mundo do trabalho docente, nas redes municipais e estaduais de ensino.

As Resenhas finalizam esta edição com duas contribuições: na primeira, Kelly Costa apresenta o livro "Escola "sem" partido: esfinge que ameaça a educação e a sociedade brasileira" (UERJ/LPP), organizado por Gaudêncio Frigotto. A segunda resenha, de autoria de Livaldo Silva e Jordan Santos, apresenta o livro "O PROEJA no Colégio Pedro II: Formação e Qualificação Docente em Questão" (RPC Editora), de autoria de Bruno Miranda Neves. leitura!

Agradecemos desde já as contribuições e desejamos a todos uma excelente

Andrea da Paixão Fernandes Christiane de Faria Pereira Arcuri Maria Beatriz Dias da Silva Maía Porto

Editoras da e-Mosaicos - Revista Multidisciplinar de Ensino, Pesquisa, Extensão e Cultura do Instituto de Aplicação Fernando Rodrigues da Silveira (CAp-UERJ) 